\title{
Coexistence of copy number increases of ZNF217 and CYP24A1 in colorectal cancers in a Chinese population
}

\author{
ZHENGYU FANG $^{1 *}$, YI XIONG ${ }^{1 *}$, CHAO ZHANG $^{1}$, JIANA LI $^{1}$, \\ LI LIU $^{1}$, MANHUI LI ${ }^{1}$, WEI ZHANG ${ }^{2}$ and JUN WAN ${ }^{1}$ \\ ${ }^{1}$ Biomedical Research Institute, Shenzhen-PKU-HKUST Medical Center and Shenzhen Hospital, Peking \\ University; ${ }^{2}$ JNU-HKUST Joint Laboratory, Ji-Nan University, Guangdong, P.R. China
}

Received May 17, 2010; Accepted July 19, 2010

DOI: 10.3892/ol_00000163

\begin{abstract}
Evidence suggests that the amplification of chromosome 20q13 is common in colorectal cancers (CRCs). Certain candidate oncogenes located in this region are reported to be associated with tumorigenesis of the gastrointestinal tract. The functional impact of such regions should be extensively investigated in a large number of clinical samples. In this study, 145 CRC samples with matched adjacent normal tissues were collected from a Chinese population for copy number variation $(\mathrm{CNV})$ analysis. Our results showed that both the copy numbers of 25-hydroxy vitamin D3 24-hydroxylase (CYP24A1) and zinc-finger protein 217 (ZNF217) were amplified in a relatively high percentage of CRC samples (51.1 and $60 \%$, respectively). The mRNA expression levels of both CYP24A1 and ZNF217 were found to have increased in the collected CRC samples as compared to the matched adjacent normal tissues. ZNF217, but not CYP24A1, showed a positive correlation between copy number increases and mRNA overexpression. These findings suggest the potential role of CNVs of certain oncogenes in CRCs.
\end{abstract}

\section{Introduction}

Colorectal cancer (CRC) is the third most common cancer in the Chinese population and causes approximately 130,000 deaths per year. The lifetime risk in the Chinese population is approximately $4.2 \%$. Both genetic and environmental factors contribute to the disease etiology, with one-third of disease variance attributed to inherited genetic factors (1). Chromosomal aberrations, such as deletions, amplifications and structural rearrangements, are hallmarks of cancer $(2,3)$.

Correspondence to: Dr Jun Wan, Biomedical Research Institute, Shenzhen-PKU-HKUST Medical Center and Shenzhen Hospital, Peking University, Guangdong, P.R. China

E-mail:wanj@ust.hk

${ }^{*}$ Contributed equally

Key words: colorectal cancer, zinc-finger protein 217, 25-hydroxy vitamin D3 24-hydroxylase, copy number variation
The implication of copy number variations (CNVs) in cancer has become a hot spot over the past few years (4-6). Studies using single nucleotide polymorphism arrays and array comparative genomic hybridization $(\mathrm{aCGH})$ have suggested that DNA amplification at the chromosome position $20 \mathrm{q}$ is common in CRCs (7-10). Gain of chromosome 20q is reported to correlate with lymph node metastasis in gastric cancer and poor clinical outcome in CRCs $(11,12)$. Moreover, copy number changes in the chromosome 20q13.2 region correlate with the metastasis of CRCs (13).

Chromosomal aberrations in tumors lead to DNA copy number alterations, with an associated gain or loss of genes crucial for tumor progression (14-18). The majority of the aCGH experiments have focused on the genome-wide screening of CNVs, and the data obtained are generally informative, but not definitive. Thus, further molecular genetic experiments are necessary for validation. Mapping of the amplified region at 20q13.2 has led to the positional cloning and characterization of zinc-finger protein 217 (ZNF217) (19) and 25-hydroxy vitamin D3 24-hydroxylase (CYP24A1) $(20,21)$, which are considered to be candidate oncogenes involved in CRCs.

ZNF217, a Rappel-like zinc-finger protein, is a candidate oncogene located at 20q13.2, within a region of recurrent maximal amplification. ZNF217 proteins localize predominantly to the nucleus and associate with proteins involved in transcriptional repression. The overexpression of ZNF217 in cultured human mammary and ovarian epithelial cells results in their immortalization (22), indicating that selection for ZNF217 expression may drive 20q13.2 amplification during critical early stages of cancer progression. The inappropriate expression of ZNF217 may lead to the aberrant down-regulation of genes involved in limiting the proliferation, survival and/or invasiveness of cancer cells (23). The CYP24A1 gene, also located at chromosome 20q13.2, encodes a member of the cytochrome P450 superfamily of enzymes. The CYP24A1 protein is considered to be the main enzyme determining the biological half-life of 1,25-D3. The overexpression of CYP24A1 reduced local 1, 25-D3 availability and decreased its anti-proliferative effect. Thus, it has been identified as a potential biomarker for colorectal tumorigenesis $(20,24)$.

In this study, 145 CRC tissues and matched adjacent normal tissues were collected for CNV analysis. The significance of the CNVs of ZNF217 and CYP24A1 in the colorectal malig- 
Table I. Comparison of copy number variations of CYP24A1 and ZNF217 between adjacent normal tissues and healthy normal controls from peripheral blood.

Copy no.

\begin{tabular}{|c|c|c|c|c|c|c|c|}
\hline & \multirow[b]{3}{*}{ No. } & \multirow{2}{*}{\multicolumn{2}{|c|}{ Deletion }} & & & & \\
\hline \multirow[b]{2}{*}{ Samples } & & & & \multirow[b]{2}{*}{2} & \multicolumn{2}{|c|}{ Amplification } & \multirow[b]{2}{*}{ P-value ${ }^{a}$} \\
\hline & & 0 & 1 & & 3 & $>3$ & \\
\hline \multicolumn{8}{|c|}{ CYP24A1 } \\
\hline HNCs & 152 & 3 & 9 & 127 & 8 & 5 & - \\
\hline ANTs & 145 & 4 & 11 & 110 & 12 & 8 & 0.583 \\
\hline \multicolumn{8}{|l|}{ ZNF217 } \\
\hline HNCs & 152 & 5 & 4 & 131 & 8 & 4 & - \\
\hline ANTs & 145 & 6 & 7 & 107 & 16 & 11 & 0.057 \\
\hline
\end{tabular}

${ }^{a}$ vs. HNCs. ANTs, adjacent normal tissues; HNCs, healthy normal controls.

nancies were examined and the coexistence of copy number increases of ZNF217 and CYP24A1 in CRC compared to the adjacent normal tissues was noted.

\section{Materials and methods}

Patients and tissue collection. Colorectal cancer samples were obtained from 145 surgical patients at the Department of Gastroenterology, Shenzhen Hospital and Peking University. Adjacent normal mucosa samples located at least $2 \mathrm{~cm}$ from the macroscopically unaffected margins of the tumor (polyp or carcinoma) were defined as normal controls. A total of 134 tumors were found to be adenocarcinomas and 11 were mucinous carcinomas (when $>50 \%$ of the tumor volume was composed of mucin). Colorectal cancers were staged according to the Dukes' classification system: Dukes' A $\left(T_{1}-T_{2}, N 0\right.$ and $\mathrm{M}_{0} ; \mathrm{n}=43$ ), Dukes' $\mathrm{B}\left(\mathrm{T}_{3}-\mathrm{T}_{4}, \mathrm{~N} 0\right.$ and $\left.\mathrm{M}_{0} ; \mathrm{n}=39\right)$, Dukes' $\mathrm{C}$ (any T, N1-2 and $\mathrm{M}_{0} ; \mathrm{n}=48$ ) and Dukes' $\mathrm{D}$ (any $\mathrm{T}$, any $\mathrm{N}$ and $\mathrm{M}_{1}$; $\mathrm{n}=15)$. Samples of colorectal carcinomas $(\mathrm{n}=145)$ and matched normal colonic mucosa $(n=145)$ were subjected to real-time PCR analysis. CRC samples were collected from patients undergoing bowel resection. The collected samples were stored in liquid nitrogen. All 145 patients were informed regarding the intent of the specimen collection and provided signed written consent in accordance with the ethical guidelines of Peking University. Bone marrow samples from 152 healthy controls were also collected at the Peking University People's Hospital. The study was approved by the Ethics Committee of Peking University, Shenzhen Hospital.

DNA extraction and quantification of copy numbers. Genomic DNA was isolated from the tissues using the Genomic DNA Extraction kit (Innocent, Shenzhen, P.R. China) according to the manufacturer's instructions. Quantitative PCR was performed using the BioRad Chromo4 real-time PCR system. Average copy numbers $(n=2)$ of RNAse $P$ in normal candidates were used as the control (13). The copy numbers of ZNF217 and CYP24A1 were calculated by using the comparative $\mathrm{C}(\mathrm{T})$ method. Cut-off values of $0.25,0.75,1.25$ and 1.75 were used to define the copy numbers as $0,1,2$ and 3 , respectively. The primers were: RNAse $P$, forward 5'-AGA CTA GGG TCA GAA GCA A-3' and reverse 5'-CAT TTC ACT GAA TCC GTT C-3'; CYP24A, forward 5'-ATA TCC AAC TCA GGG AAG CG-3' and reverse 5'-GAA GAT GGT GCT GAC ACA GG-3'; and ZNF217, forward 5'-TCC ATA GAG CAA GGG TAA TCC-3' and reverse 5'-TGC CAA CAG ACT GAT CTC AA-3'.

The fold change of each sample was presented as: fold change $=$ relative expression level/average expression level in the group with two copies of DNA.

RNA extraction and real-time PCR. Total RNA was isolated from tissues using the AxyPrep ${ }^{\mathrm{TM}}$ Blood Total RNA MiniPrep kit (Axygen) according to the manufacturer's instructions. First strand cDNA was synthesized with the RevertAid ${ }^{\mathrm{TM}}$ First Stand cDNA Synthesis kit (Fermentas). Quantitative PCR was performed using the BioRad Chromo4 real-time PCR system. At the endpoint of PCR cycles, melting curves were constructed to check product purity. The mRNA level of ZNF217 and CYP24A1 was expressed as a ratio relative to the GAPDH mRNA in each sample. Exploratory data analysis using box plots was applied to visually identify the expression level of target mRNA.

Statistical analysis. Stastistical analysis was performed using the Chi-square or Fisher's exact test. $\mathrm{P}<0.05$ was considered to be statistically significant.

\section{Results}

Gene copy number gains of ZNF217 and CYP24A1 in CRC samples. To investigate whether the CNVs of ZNF217 and CYP24A1 in CRCs were acquired or inherited DNA aberrations, we collected 152 genomic DNA samples from healthy individuals for $\mathrm{CNV}$ analysis and compared them to the adjacent normal tissues (ANTs) from the CRC patients. As shown in Table I, no statistical difference in copy number distribution between the ANTs and healthy normal controls was observed, which indicated that the CNVs of the two genes in CRCs were more likely to be 'acquired'. Moreover, ANTs may have been used as controls for the cancer tissues in this study. 
Table II. Copy number variations of CYP24A1 and ZNF217 in colorectal cancer tissues and matched adjacent normal tissues.

\begin{tabular}{|c|c|c|c|c|c|}
\hline \multirow[t]{3}{*}{ CNV population } & \multirow[t]{3}{*}{ No. } & \multicolumn{2}{|c|}{ Copy no. } & \multirow[t]{3}{*}{ P-value } & \multirow[t]{3}{*}{ P-value } \\
\hline & & \multirow[b]{2}{*}{$\leq 2$} & \multirow{2}{*}{$\frac{\text { Amplification }}{>2}$} & & \\
\hline & & & & & \\
\hline \multicolumn{6}{|l|}{ CYP24A1 } \\
\hline \multicolumn{6}{|l|}{ Total } \\
\hline ANTs & 145 & 125 & 20 & - & - \\
\hline CRCs & & 71 & 74 & $1.25 \mathrm{E}-11$ & - \\
\hline \multicolumn{6}{|l|}{ Dukes' A } \\
\hline ANTs & 43 & 39 & 4 & - & - \\
\hline CRCs & & 28 & 15 & $5.40 \mathrm{E}-5$ & - \\
\hline \multicolumn{6}{|l|}{ Dukes' B } \\
\hline ANTs & 39 & 33 & 6 & - & - \\
\hline CRCs & & 16 & 23 & $1.59 \mathrm{E}-5$ & $2.89 \mathrm{E}-2$ \\
\hline \multicolumn{6}{|l|}{ Dukes' C and D } \\
\hline ANTs & 63 & 56 & 7 & - & - \\
\hline CRCs & & 27 & 36 & $2.84 \mathrm{E}-7$ & $2.43 \mathrm{E}-2$ \\
\hline \multicolumn{6}{|l|}{ ZNF217 } \\
\hline \multicolumn{6}{|l|}{ Total } \\
\hline ANTs & 145 & 118 & 27 & - & - \\
\hline CRCs & & 58 & 87 & $5.46 \mathrm{E}-13$ & - \\
\hline \multicolumn{6}{|l|}{ Dukes' A } \\
\hline ANTs & 43 & 34 & 9 & - & - \\
\hline CRCs & & 25 & 18 & $3.65 \mathrm{E}-3$ & - \\
\hline \multicolumn{6}{|l|}{ Dukes' B } \\
\hline ANTs & 39 & 32 & 7 & - & - \\
\hline CRCs & & 13 & 26 & $1.30 \mathrm{E}-6$ & $2.44 \mathrm{E}-2$ \\
\hline \multicolumn{6}{|l|}{ Dukes' C and D } \\
\hline ANTs & 63 & 52 & 11 & - & - \\
\hline CRCs & & 20 & 43 & 8.38E-9 & $6.94 \mathrm{E}-3$ \\
\hline
\end{tabular}

${ }^{a}$ vs. ANTs; ${ }^{b} v s$. Dukes' A. ANTs, adjacent normal tissues; CRCs, colorectal cancer tissues.

Table II shows the CNVs of ZNF217 and CYP24A1 in CRC samples and the matched ANTs. A total of $145 \mathrm{CRC}$ samples were examined. A relatively high percentage of CRC samples showed an amplification of CYP24A1 (51.1\%, 74 out of 145) and ZNF217 (60\%, 87 out of 145). A copy number increase of ZNF217 and CYP24A1 was observed in all stages of $\mathrm{CRC}$, and a significant correlation was found between the gene copy number gains of CYP24A1 and ZNF217 and tumor progression $(\mathrm{P}<0.05)$. Co-existent increases of CYP24A1 and ZNF217 were found in a relatively high percentage of CRC samples with copy number amplification of CYP24A1 $(64.7 \%$, 33 out 51) and ZNF217 (55.9\%, 33 out of 59).

ZNF217, but not CYP24A1, shows a positive correlation between copy number increases and $m R N A$ overexpression. To determine whether the CNVs of ZNF217 and CYP24A1 have a genotype-phenotype correlation in CRCs, we first compared the mRNA expression levels of CYP24A1 and ZNF217 between the CRC samples and the matched ANTs by quantitative real-time RT-PCR. As shown in Fig. 1A and B, increased mRNA expression levels of both CYP24A1 and ZNF217 were observed in the CRC tissues compared to the ANTs. These results were consistent with previous findings $(19,20)$.

Gene CNVs contribute to qualitative and quantitative diversities in their gene products. We selected the samples with increased or unaltered copies of ZNF217 and CYP24A1 and tested whether the mRNA expression levels of ZNF217 and CYP24A1 correlated with the copy numbers. The samples with decreased copies of CYP24A1 (7 out of 145) and ZNF217 (4 out of 145) were not included due to the small sample size. As shown in Fig. 1C and D, the CRC samples in the group with amplified copies of CYP24A1 and ZNF217 showed a markedly increased mRNA expression compared to the ANTs $(\mathrm{P}<0.01)$. However, the groups with unaltered copies of CYP24A1 and ZNF217 also showed a relatively increased mRNA expression in the CRC samples $(\mathrm{P}<0.05)$. No significantly statistical difference in the mRNA expression was present between the CRC samples in the groups with amplified and unaltered copies of CYP24A1 $(\mathrm{P}=0.092)$. By contrast, the group with DNA amplification of ZNF217 showed an increased mRNA expression compared to that with unaltered DNA copies $(\mathrm{P}<0.05)$. 
A

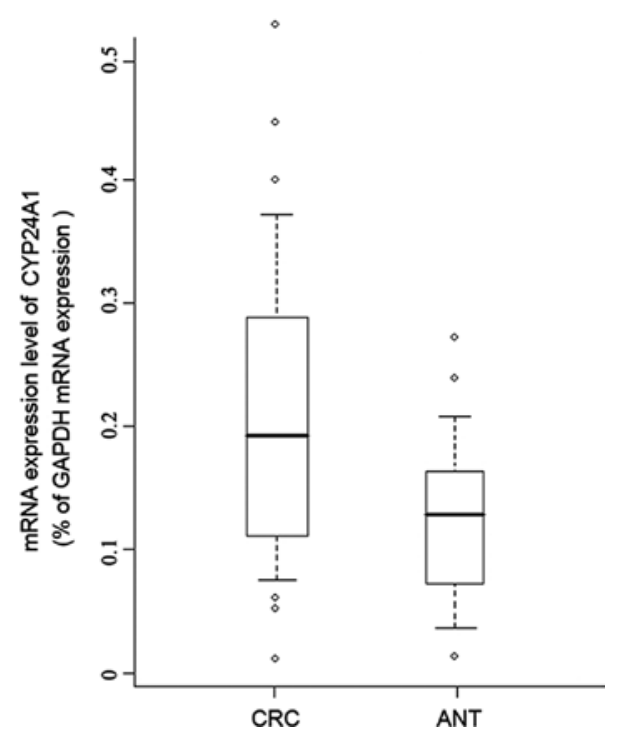

C

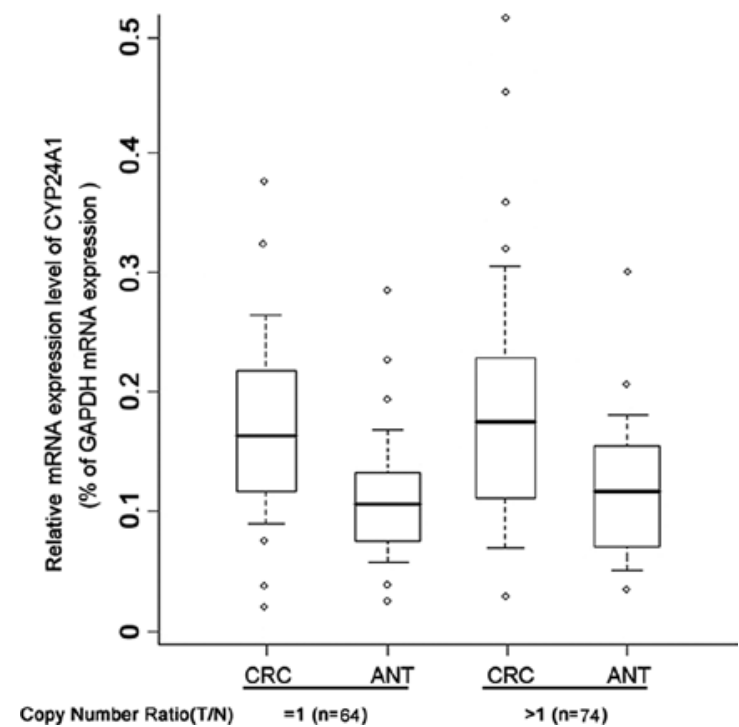

B

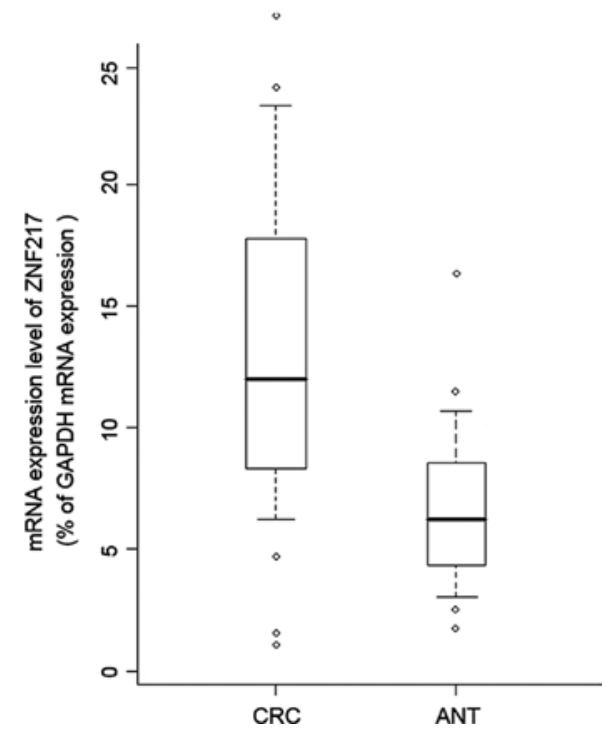

D

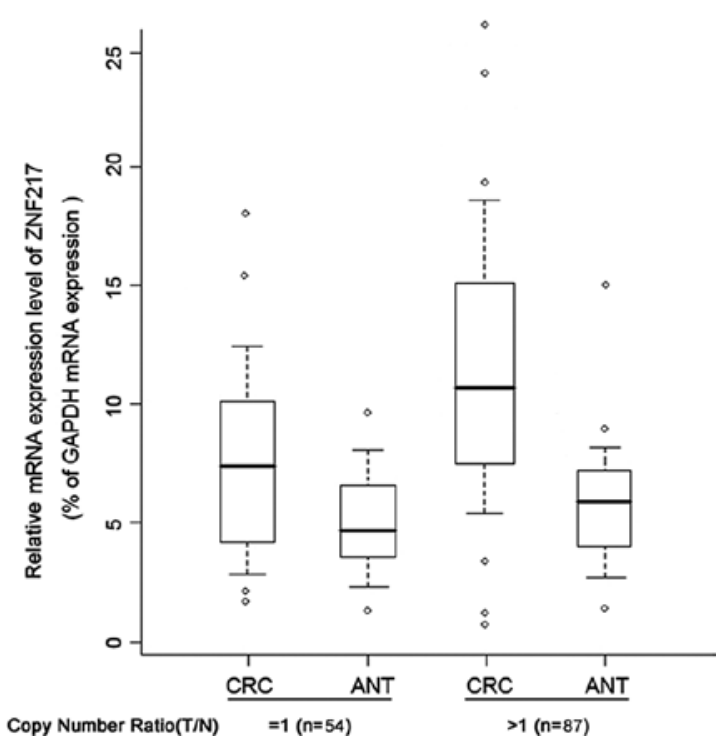

Figure 1. Real-time PCR assay was carried out as described in Materials and methods, and the results were obtained from an indicated group of samples. Box plots of a relative copy number of ITGA5 mRNA measured with real-time PCR analysis show the median; box, 25-75th percentile; bars, largest and smallest values within 1.5 box lengths; little circles, outliers. (A) mRNA expression level of CYP24A1 in all of the colorectal cancer (CRC) samples compared to the adjacent normal tissues (ANTs). (B) mRNA expression level of ZNF217 in all of the CRC samples compared to the ANTs. (C) mRNA expression level of CYP24A1 in the groups with amplified or unaltered DNA copies. (D) mRNA expression level of ZNF217 in the groups with amplified or unaltered DNA copies.

\section{Discussion}

Although cancer is widely regarded as an acquired disease, familial predisposition plays a significant role in many cancer types. A number of highly penetrant cancer-predisposing genes correlated with CRC have been identified [DNA mismatch repair genes (25), APC, SMAD4, BMPR1A and MUTYH (26)]. However, these genes explain only a fraction of the familial and/or hereditary cases of cancer. CNVs identified by CGH and array technology have the potential to directly or indirectly impact the susceptibility of a healthy individual to cancer, for example by varying the gene dosage of tumor suppressors or oncogenes $(14,27)$. However, many discrepancies exist among previous studies which used high-resolution approaches to screen CNVs (28-32). Thus, validation of such CNVs using a large number of clinical samples is required.
It has been suggested that the genes present in very small regions of CNVs are excellent candidates for evaluation in cancer pathogenesis (33). Examination of the CNVs for such genes aids in the understanding of the roles these CNVs play. A previous study found that the chromosome 20q13.2 region involving ZNF217 and CYP24A1 was amplified in CRC samples (13). Findings of this study showed that the amplification of ZNF217 (87 out of 145) and CYP24A1 (74 out of 145) was common in CRC samples in the Chinese patient population studied. Furthermore, CNVs of CYP24A1 and ZNF217 were found to correlate with gastric cancer progression. Co-existent increases of CYP24A1 and ZNF217 were found in a relatively high percentage of CRC samples with copy number changes, which may be due to the co-localization of these changes on the chromosome. However, we found that ZNF217 and CYP24A1 were also deleted in a small percentage of samples (4 and 7 out of 145, respectively). This discrepancy may be due 
Table III. The samples with an inversed correlation between copy number and mRNA expression.

\begin{tabular}{|c|c|c|c|c|}
\hline \multirow[t]{2}{*}{ Sample no. } & \multirow[t]{2}{*}{ Gene } & \multicolumn{2}{|c|}{ Gene copy no. } & \multirow{2}{*}{$\begin{array}{c}2^{-\Delta \Delta c t} \text { representing relative mRNA } \\
\text { of cancer tissues (fold) }\end{array}$} \\
\hline & & ANTs & Cancer tissues & \\
\hline 14 & $\begin{array}{l}\text { CYP24A1 } \\
\text { ZNF217 }\end{array}$ & $\begin{array}{l}2 \\
2\end{array}$ & $\begin{array}{l}7 \\
5\end{array}$ & $\begin{array}{l}0.268401 \\
0.178860\end{array}$ \\
\hline 39 & $\begin{array}{l}\text { CYP24A1 } \\
\text { ZNF217 }\end{array}$ & $\begin{array}{l}2 \\
2\end{array}$ & $\begin{array}{l}46 \\
20\end{array}$ & $\begin{array}{l}2.482067 \\
0.568652\end{array}$ \\
\hline 40 & $\begin{array}{l}\text { CYP24A1 } \\
\text { ZNF217 }\end{array}$ & $\begin{array}{l}1 \\
2\end{array}$ & $\begin{array}{r}42 \\
109\end{array}$ & $\begin{array}{l}0.001883 \\
2.981663\end{array}$ \\
\hline 45 & $\begin{array}{l}\text { CYP24A1 } \\
\text { ZNF217 }\end{array}$ & $\begin{array}{l}3 \\
4\end{array}$ & $\begin{array}{l}20 \\
10\end{array}$ & $\begin{array}{r}49.011700 \\
0.763486\end{array}$ \\
\hline 51 & $\begin{array}{l}\text { CYP24A1 } \\
\text { ZNF217 }\end{array}$ & $\begin{array}{l}2 \\
2\end{array}$ & $\begin{array}{r}125 \\
37\end{array}$ & $\begin{array}{l}0.098165 \\
0.143144\end{array}$ \\
\hline 82 & $\begin{array}{l}\text { CYP24A1 } \\
\text { ZNF217 }\end{array}$ & $\begin{array}{l}2 \\
2\end{array}$ & $\begin{array}{l}8 \\
7\end{array}$ & $\begin{array}{l}0.053129 \\
0.676848\end{array}$ \\
\hline
\end{tabular}

ANTs, adjacent normal tissues.

to the different races and populations used in the studies as well as the different research methodologies. In contrast, we used a gene-specific strategy to target short fragments (several hundred base-pairs) with an increase in sensitivity.

CNVs are considered to have a genotype-phenotype correlation. Phenotypic effects of genetic differences, such as CNVs, are likely to be caused by changes in expression levels (34-36). We investigated the correlation between the mRNA expression levels of ZNF217 and CYP24A and the copy numbers of their DNA. Notably, the correlation was not as positive as expected, although a statistical difference was obtained. This result is consistent with two recent reports which assessed an over-representation of differentially expressed genes among CNV-mapping transcripts and observed a weak but significant positive correlation between the relative expression level and gene dosage $(37,38)$. In the present study, the CRC samples with increased CYP24A1 copies showed an enhanced expression level of mRNA, similar to the samples with unaltered DNA copies. The significantly altered CYP24A1 expression in CRCs may be due mainly to another mechanism (such as methylation). However, in the case of ZNF217, a statistical difference in mRNA expression was observed between the groups with amplified and unaltered DNA copies. CNVs thus played a role in the overexpression of the ZNF217 mRNA in CRCs.

In a small percentage of samples, the recorded relative expression levels were inversely correlated with copy numbers (Table III). This type of inverse correlation was also noted in previous studies $(37,38)$. The mechanism of this phenomenon is poorly understood, but may be elucidated by two models. In the first model, a negative correlation between the number of copies and relative expression is explained by immediate early genes, which directly or indirectly induce the expression of a repressor that, by a negative feedback loop, reduces or even abolishes the expression of the CNV gene. In the second model, the extra copies of a gene impair, through steric hinderance, the access of genes to a specific transcription factor, where this particular locus should be transcribed (39).

Taken together, our findings showed that the CNVs of ZNF217 and CYP24A1 have the potential to serve as diagnostic indicators for colorectal malignancies, alone or in combination with other markers. A copy number increase of ZNF217 was correlated with the overexpression of mRNA in the CRCs. However, the role of CNVs, the different characteristics of CNVs between colorectal and other gastrointestinal malignancies and the underlying mechanisms of the heterogeneous expression levels require extensive investigation in the future.

\section{References}

1. Lichtenstein P, Holm NV, Verkasalo PK, Iliadou A, Kaprio J, Koskenvuo M, Pukkala E, Skytthe A and Hemminki K: Environmental and heritable factors in the causation of canceranalyses of cohorts of twins from Sweden, Denmark, and Finland. N Engl J Med 343: 78-85, 2000.

2. Pinkel D and Albertson DG: Comparative genomic hybridization. Annu Rev Genomics Hum Genet 6: 331-354, 2005.

3. Hupe P, Stransky N, Thiery JP, Radvanyi F and Barillot E: Analysis of array CGH data: from signal ratio to gain and loss of DNA regions. Bioinformatics 20: 3413-3422, 2004.

4. Andrews J, Kennette W, Pilon J, Hodgson A, Tuck AB, Chambers AF and Rodenhiser DI: Multi-platform whole-genome microarray analyses refine the epigenetic signature of breast cancer metastasis with gene expression and copy number. PLoS One 5: e8665, 2010.

5. Diskin SJ, Hou C, Glessner JT, et al: Copy number variation at 1q21.1 associated with neuroblastoma. Nature 459: 987-991, 2009.

6. Liu W, Sun J, Li G, et al: Association of a germ-line copy number variation at $2 \mathrm{p} 24.3$ and risk for aggressive prostate cancer. Cancer Res 69: 2176-2179, 2009.

7. Nakao K, Mehta KR, Fridlyand J, Moore DH, Jain AN, Lafuente A, Wiencke JW, Terdiman JP and Waldman FM: High-resolution analysis of DNA copy number alterations in colorectal cancer by array-based comparative genomic hybridization. Carcinogenesis 25: 1345-1357, 2004. 
8. Ashktorab H, Schaffer AA, Daremipouran M, Smoot DT, Lee E and Brim H: Distinct genetic alterations in colorectal cancer. PLoS One 5: e8879, 2010.

9. Carvalho B, Postma C, Mongera S, et al: Multiple putative oncogenes at the chromosome $20 \mathrm{q}$ amplicon contribute to colorectal adenoma to carcinoma progression. Gut 58: 79-89, 2009.

10. De Angelis PM, Stokke T, Beigi M, et al: Chromosomal 20c gain in the DNA diploid component of aneuploid colorecta carcinomas. Int J Cancer 120: 2734-2738, 2007.

11. Aust DE, Muders M, Kohler A, Schmidt M, Diebold J, Muller C, Lohrs U, Waldman FM and Baretton GB: Prognostic relevance of 20q13 gains in sporadic colorectal cancers: a FISH analysis. Scand J Gastroenterol 39: 766-772, 2004.

12. Postma C, Terwischa S, Hermsen MA, van der Sijp JR and Meijer GA: Gain of chromosome 20q is an indicator of poor prognosis in colorectal cancer. Cell Oncol 29: 73-75, 2007.

13. Hidaka $S$, Yasutake $T$, Takeshita $H$, Kondo $M$, Tsuji $T$, Nanashima A, Sawai T, Yamaguchi H, Nakagoe T, Ayabe $H$ and Tagawa Y: Differences in 20q13.2 copy number between colorectal cancers with and without liver metastasis. Clin Cancer Res 6: 2712-2717, 2000.

14. Dear PH: Copy-number variation: the end of the human genome? Trends Biotechnol 27: 448-454, 2009.

15. John T, Liu G and Tsao MS: Overview of molecular testing in non-small-cell lung cancer: mutational analysis, gene copy number, protein expression and other biomarkers of EGFR for the prediction of response to tyrosine kinase inhibitors. Oncogene 28 (Suppl 1): 14-23, 2009

16. Sanchez-Cespedes M: The impact of gene expression microarrays in the evaluation of lung carcinoma subtypes and DNA copy number. Arch Pathol Lab Med 132: 1562-1565, 2008.

17. Speleman F, Kumps C, Buysse K, Poppe B, Menten B and De Preter K: Copy number alterations and copy number variation in cancer: close encounters of the bad kind. Cytogenet Genome Res 123: 176-182, 2008.

18. Venkatachalam R, Ligtenberg MJ, Hoogerbrugge $\mathrm{N}$ Geurts van Kessel A and Kuiper RP: Predisposition to colorectal cancer: exploiting copy number variation to identify novel predisposing genes and mechanisms. Cytogenet Genome Res 123: 188-194, 2008

19. Rooney PH, Boonsong A, McFadyen MC, McLeod HL, Cassidy J, Curran S and Murray GI: The candidate oncogene ZNF217 is frequently amplified in colon cancer. J Pathol 204: 282-288, 2004

20. Horvath HC, Lakatos P, Kosa JP, Bacsi K, Borka K, Bises G, Nittke T, Hershberger PA, Speer G and Kallay E: The candidate oncogene CYP24A1: A potential biomarker for colorectal tumorigenesis. J Histochem Cytochem 58: 277-285, 2010.

21. McCullough ML, Bostick RM and Mayo TL: Vitamin D gene pathway polymorphisms and risk of colorectal, breast, and prostate cancer. Annu Rev Nutr 29: 111-132, 2009.

22. Li P, Maines-Bandiera S, Kuo WL, Guan Y, Sun Y, Hills M, Huang G, Collins CC, Leung PC, Gray JW and Auersperg N Multiple roles of the candidate oncogene ZNF217 in ovarian epithelial neoplastic progression. Int J Cancer 120: 1863-1873, 2007.

23. Quinlan KG, Verger A, Yaswen P and Crossley M: Amplification of zinc finger gene 217 (ZNF217) and cancer: when good fingers go bad. Biochim Biophys Acta 1775: 333-340, 2007.
24. King AN, Beer DG, Christensen PJ, Simpson RU and Ramnath N: The vitamin D/CYP24A1 story in cancer. Anticancer Agents Med Chem 10: 213-224, 2010.

25. Barnetson RA, Tenesa A, Farrington SM, Nicholl ID, Cetnarskyj R, Porteous ME, Campbell $\mathrm{H}$ and Dunlop MG: Identification and survival of carriers of mutations in DNA mismatch-repair genes in colon cancer. $\mathrm{N}$ Engl J Med 354: 2751-2763, 2006

26. Tenesa A, Campbell H, Barnetson R, Porteous M, Dunlop M and Farrington SM: Association of MUTYH and colorectal cancer. Br J Cancer 95: 239-242, 2006.

27. Shlien A, Tabori U, Marshall CR, Pienkowska M, Feuk L, Novokmet A, Nanda S, Druker H, Scherer SW and Malkin D: Excessive genomic DNA copy number variation in the Li-Fraumeni cancer predisposition syndrome. Proc Natl Acad Sci USA 105: 11264-11269, 2008.

28. Grubor V, Krasnitz A, Troge JE, et al: Novel genomic alterations and clonal evolution in chronic lymphocytic leukemia revealed by representational oligonucleotide microarray analysis (ROMA). Blood 113: 1294-1303, 2009.

29. Gunnarsson R, Staaf J, Jansson M, et al: Screening for copynumber alterations and loss of heterozygosity in chronic lymphocytic leukemia - a comparative study of four differently designed, high resolution microarray platforms. Genes Chromosomes Cancer 47: 697-711, 2008.

30. Schafer M, Schwender H, Merk S, Haferlach C, Ickstadt K and Dugas $\mathrm{M}$ : Integrated analysis of copy number alterations and gene expression: a bivariate assessment of equally directed abnormalities. Bioinformatics 25: 3228-3235, 2009.

31. Strefford JC, van Delft FW, Robinson HM, et al: Complex genomic alterations and gene expression in acute lymphoblastic leukemia with intrachromosomal amplification of chromosome 21. Proc Natl Acad Sci USA 103: 8167-8172, 2006.

32. Sulong S, Moorman AV, Irving JA, et al: A comprehensive analysis of the CDKN2A gene in childhood acute lymphoblastic leukemia reveals genomic deletion, copy number neutral loss of heterozygosity, and association with specific cytogenetic subgroups. Blood 113: 100-107, 2009.

33. Ionita-Laza I, Rogers AJ, Lange C, Raby BA and Lee CI: Genetic association analysis of copy-number variation $(\mathrm{CNV})$ in human disease pathogenesis. Genomics 93: 22-26, 2009.

34. Henrichsen CN, Chaignat E and Reymond A: Copy number variants, diseases and gene expression. Hum Mol Genet 18: R1-R8, 2009.

35. Dermitzakis ET and Stranger BE: Genetic variation in human gene expression. Mamm Genome 17: 503-508, 2006.

36. Reymond A, Henrichsen CN, Harewood L and Merla G: Side effects of genome structural changes. Curr Opin Genet Dev 17: 381-386, 2007.

37. Guryev V, Saar K, Adamovic T, et al: Distribution and functional impact of DNA copy number variation in the rat. Nat Genet 40: 538-545, 2008.

38. Henrichsen $\mathrm{CN}$, Vinckenbosch $\mathrm{N}$, Zollner S, Chaignat $\mathrm{E}$, Pradervand S, Schutz F, Ruedi M, Kaessmann H and Reymond A: Segmental copy number variation shapes tissue transcriptomes. Nat Genet 41: 424-429, 2009.

39. Sexton T, Umlauf D, Kurukuti S and Fraser P: The role of transcription factories in large-scale structure and dynamics of interphase chromatin. Semin Cell Dev Biol 18: 691-697, 2007. 